\title{
Current and Future Use of Adaptive Servo-Ventilation
}

\author{
Marie-Pia d'Ortho, ${ }^{1,2}$ Holger Woehrle ${ }^{3,4}$ and Michael Arzt ${ }^{5}$ \\ 1. University Paris Diderot, UFR de Médicine, Sorbonne Paris Cité, Paris, France; 2. Hôpital Bichat, Explorations Fonctionnelles, DHU FIRE, AP-HP, Paris, France; \\ 3. Sleep and Ventilation Center Blaubeuren, Respiratory Center UIm, UIm, Germany; 4. ResMed Science Center, ResMed Germany Inc., Martinsried, Germany; \\ 5. Department of Internal Medicine II, Cardiology and Pneumology, University Hospital Regensburg, Germany
}

DOI: http://doi.org/10.17925/ERPD.2016.02.01.1

\begin{abstract}
Adaptive servo-ventilation (ASV) is a form of non-invasive positive airway pressure (PAP) therapy that differs from other PAP devices. It includes features to overcome both obstructive and central sleep-disordered breathing (SDB) events. In the Treatment of Sleep-Disordered Breathing with Predominant Central Sleep Apnea by Adaptive Servo-Ventilation in Patients with Heart Failure (SERVE-HF) Study, ASV significantly reduced SDB events in patients with systolic heart failure (HF) and predominant central sleep apnoea (CSA), but did not improve outcomes, and there was increased mortality risk in the ASV group. Although the SERVE-HF results represent a paradigm shift for ASV, they are only applicable to a small subset of ASV-treated patients, and there is no evidence suggesting that ASV use should stop altogether. There are a number of other indications and patient groups for whom ASV may be useful, effective and safe, including patients with treatment-emergent CSA, central apnoeas associated with long-term opioid therapy without alveolar hypoventilation, idiopathic Cheyne-Stokes respiration, after ischaemic stroke and those with HF with preserved ejection fraction. Additional research is required to better define the mechanism of increased risk associated with ASV identified in SERVE-HF and to more clearly characterise the specific patient phenotypes who benefit from ASV therapy.
\end{abstract}

\section{Keywords}

Adaptive servo-ventilation, central sleep apnoea, treatment-emergent sleep apnoea, opioids, stroke, heart failure

\begin{abstract}
Disclosure: Marie-Pia d'Ortho has received grants from Fisher \& Paykel Healthcare and ADEP Assistance, grants and personal fees from ResMed, Philips Respironics and IP Sante and personal fees and non-financial support from Vitalaire. Holger Woehrle is an employee of ResMed Germany. Michael Arzt has received unrestricted grant support from Philips Home Healthcare Solutions, ResMed Germany and the German Foundation for Cardiac Research (Deutsche Stiftung für Herzforschung); he is also the holder of an endowed professorship from the Free State of Bavaria at the University of Regensburg that was donated by Philips Home Healthcare Solutions and ResMed Germany. Acknowledgements: Medical writing assistance was provided by Nicola Ryan, independent medical writer, funded by RedMed.

Open Access: This article is published under the Creative Commons Attribution Noncommercial License, which permits any non-commercial use, distribution, adaptation and reproduction provided the original author(s) and source are given appropriate credit.

Received: 22 November 2015 Accepted: 11 December 2015 Citation: European Respiratory \& Pulmonary Diseases, 2016;2(1):Epub ahead of print

Correspondence: Marie-Pia d'Ortho, Service de Physiologie Explorations Fonctionnelles, Hôpital Bichat - University Paris Diderot, Sorbonne Paris Cité, DHU FIRE, AP-HP, 48 rue Henri Huchard, 75018 Paris, France. E: marie-pia.dortho@bch.aphp.fr
\end{abstract}

Support: The publication of this article was supported by ResMed. The views and opinions expressed are those of the author and do not necessarily reflect those of ResMed.

Adaptive servo-ventilation (ASV) is a non-invasive ventilatory therapy that provides variable inspiratory positive airway pressure (IPAP) to support inspiration when breathing amplitude is reduced, ensures sufficient respiration when respiratory effort is absent and provides fixed or variable end-expiratory PAP (EPAP) to maintain upper airway patency. This approach is designed to mimic nasal continuous PAP (CPAP) in terms of pneumatically opening the upper airway and to directly suppress central sleep apnoeas without causing overventilation. ${ }^{1}$ In hypocapnic central sleep apnoea (CSA), where hyperventilation plays a major role, ASV has been shown to slightly increase carbon dioxide levels in patients with heart failure (HF). ${ }^{1}$

The pressure profile provided by ASV devices differs from those of other PAP therapies (see Figure 1). Although default settings are available, sleep laboratory-based individualised titration for each patient is more appropriate, ${ }^{2}$ and the best approach to maintain patient comfort, maximise adherence and preserve haemodynamics is to use minimum effective settings for IPAP, EPAP and back-up rate. ${ }^{3}$

\section{Latest Trial Data on Adaptive Servo-Ventilation}

In general, data on the use of ASV devices have come from small and/or uncontrolled studies and mainly from sleep clinics. This changed recently with the publication of the results of the SERVE-HF trial. ${ }^{4}$

SERVE-HF was the first long-term, randomised, controlled, international multicentre phase IV trial designed to investigate the effects of adding ASV to guideline-based medical management compared with medical management alone (control) on survival and cardiovascular outcomes in patients with symptomatic HF and reduced ejection fraction (EF) (HFrEF; EF $\leq 45 \%$ ) who had predominant CSA. The ability of ASV therapy to significantly reduce the apnoea-hypopnoea index (AHI) and improve oxygen saturation and other sleep-disordered breathing (SDB) parameters was confirmed in SERVE-HF, but these effects did not translate into improved clinical outcomes. ${ }^{4}$

Unexpectedly, the trial results were neutral for the primary endpoint - first event of the composite of death from any cause, a life-saving cardiovascular intervention (defined as cardiac transplantation, 


\section{Figure 1: Characteristics of Different Positive Airway Pressure Therapies}

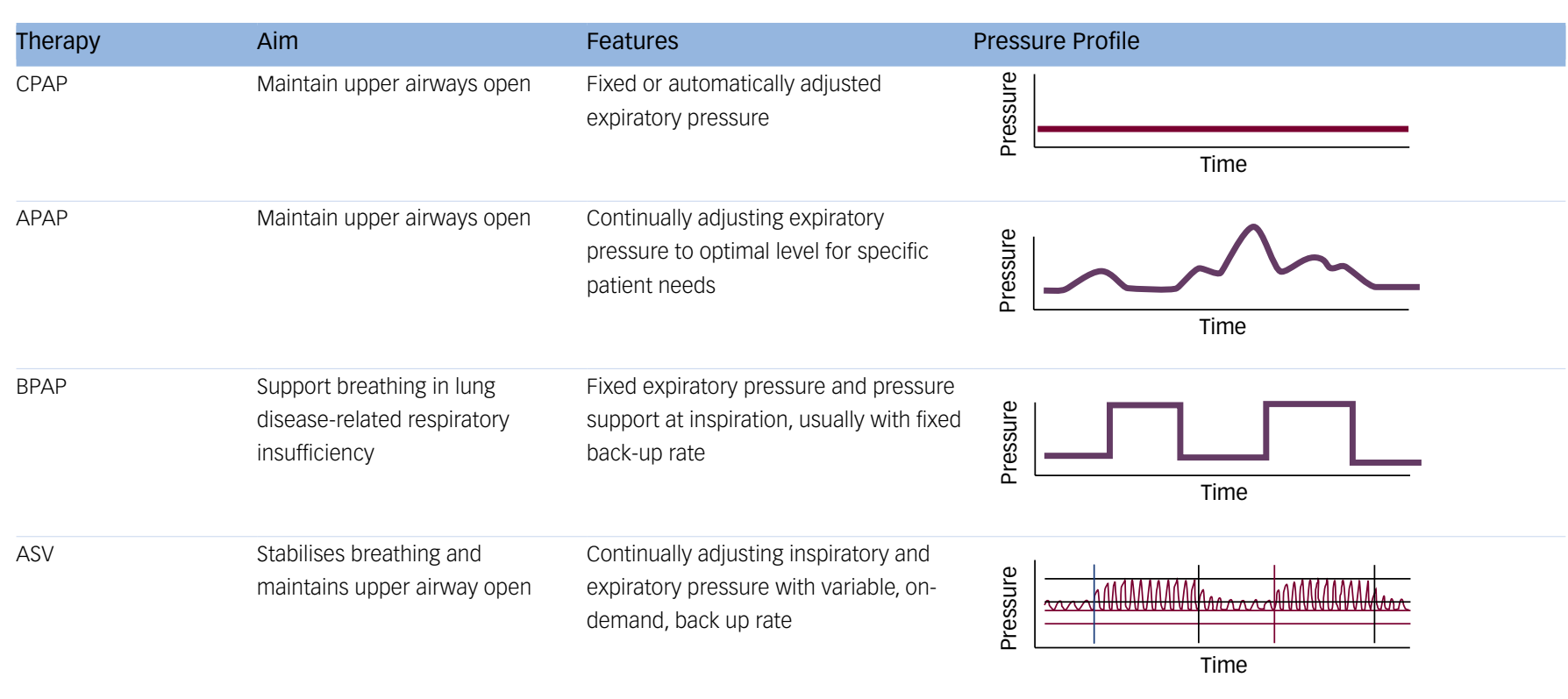

$\overline{A P A P}=$ auto-adjusting positive airway pressure; $A S V=$ adaptive servo-ventilation; BPAP = bilevel positive airway pressure; $C P A P=$ continuous positive airway pressure.

implantation of a long-term ventricular assist device, resuscitation after sudden cardiac arrest or appropriate shock for ventricular arrhythmia in patients with an implanted cardioverter defibrillator) or an unplanned hospitalisation for worsening $\mathrm{HF}$ - with a hazard ratio (HR) of 1.13 (95 \% confidence interval [Cl] 0.97, 1.32; $\mathrm{p}=0.113$ ). ${ }^{4}$ Perhaps even more surprising was the identification of a safety signal in the ASV group, with device-treated patients at higher risk of experiencing all-cause (HR 1.28, $95 \% \mathrm{Cl} 1.06,1.55 ; \mathrm{p}=0.01)$ and cardiovascular (HR 1.34, $95 \% \mathrm{Cl} 1.09$, $1.65 ; p=0.006$ ) death. ${ }^{4}$ There were no significant differences between the ASV and control groups with respect to symptoms, exercise capacity or quality of life. The effects of ASV on blood gases, left ventricular EF and biomarkers are being assessed in the SERVE-HF major substudy (NCT01164592), ${ }^{5}$ the results of which will be available soon. Such data may help to better explain the main SERVE-HF findings.

Although the SERVE-HF results represent a paradigm shift for ASV, they are only applicable to a subset of ASV-treated patients (i.e. those with $\mathrm{HFrEF}$ [EF $\leq 45 \%$ ] and predominant CSA), and there is not any evidence to suggest a need to stop considering this therapy altogether. ASV has been studied in other indications, and accumulating evidence suggests that ASV may have a role in a number of patient groups outside those with HFrEF.

\section{Adaptive Servo-Ventilation in Heart Failure with Preserved Ejection Fraction}

Although the negative prognostic impact of HF with preserved $\mathrm{EF}$ (HFPEF) is similar to that of $\mathrm{HFrEF}^{6}$ the two forms of $\mathrm{HF}$ represent different clinical syndromes and therefore should be studied and treated separately. HFpEF is more common in women and more often has a non-ishaemic aetiology, ${ }^{6,8}$ and there are currently no evidencebased treatments available. ${ }^{8}$ In addition, there are important differences between HFpEF and HFrEF with respect to the acuteness and extent of myocardial dysfunction, patterns of remodelling in heart chambers and at the ultrastructural level, and in the response to therapeutic interventions.? As a result of these differences, outcomes during ASV therapy in patients with HFpEF would be expected to be different from those of the SERVE-HF study population who had HFrEF.
The results of two small-scale studies ${ }^{9,10}$ with follow-up periods of 12 and 18 months, respectively, suggest that the beneficial effects of ASV in patients with HFpEF might extend beyond improvements in the AHI and sleep parameters. In one study, HFpEF patients with cheyne-Stokes respiration (CSR) who were treated with ASV $(n=39)$ were compared with similar patients who refused ASV for various reasons $(n=21)$ over a follow-up of 3-24 (mean 11.6) months. ${ }^{9}$ Sleep study results showed that ASV significantly reduced the AHI, longest apnoea and hypopnoea and maximum desaturation compared with controls. In addition, during cardiopulmonary exercise testing, patients in the ASV versus control group had significant increases in peak oxygen uptake (absolute value and percent predicted), oxygen uptake at the aerobic-anaerobic threshold and oxygen pulse. Significant decreases in left atrial diameter and peak early Doppler mitral inflow velocity (E)/peak atrial Doppler mitral inflow velocity (A), plus significant increases in A, mean early diastolic lengthening velocity ( $\left.e^{\prime}\right)$ and E/e' were also reported.

In a randomised study that included 36 stable HFpEF patients with central SDB the cardiac event rate was compared between patients who received optimised medical treatment alone versus optimised medical treatment plus ASV (mean follow-up 543 days). A cardiac event was defined as cardiac death or rehospitalisation for HF decompensation. Over 6 months of treatment, HFpEF patients in the ASV group had a higher event-free rate (94.4\%) than those in the no ASV group $161.1 \%$; $\mathrm{p}<0.05){ }^{10}$ Significantly greater improvements from baseline were also documented in B-type natriuretic peptide levels and New York Heart Association (NYHA) functional class in the ASV versus no ASV groups, but there was no significant change in echocardiographically determined left ventricular EF from baseline to 6 months. From an SDB perspective, reductions from baseline in the $\mathrm{AHI}$ were $30.2 / \mathrm{h}$ in the ASV group versus $8.2 / h$ in the no ASV group ( $<<0.001$ ); corresponding reductions the central apnoea index (CAl) and hypopnoea index were 9.0/h versus $4.3 / h(p=0.045)$ and $12.0 / h$ versus $1.2 / h(p=0.011) .^{10}$

It is possible that the increased sudden cardiac death rate associated with ASV treatment of CSA in patients with HFrEF identified in SERVE$\mathrm{HF}^{4}$ might be different in $\mathrm{HFPEF}$, where the underlying risk of sudden 


\section{Table 1: Summary of Major Findings of Studies Assessing Adaptive Servo-Ventilation in Patients with Treatment-emergent Central Sleep Apnoea}

\begin{tabular}{|c|c|c|c|}
\hline Author (Date) Reference & $\mathrm{N}(\mathrm{ASV})$ & ASV Duration & SDB outcomes for ASV versus controla or baseline ${ }^{b}$ \\
\hline Brill et al. (2014) 34 & 15 & 6 months & $\begin{array}{l}\text { AHI } 46.7 / h \text { versus } 10.7 / h(p=0.024)^{b} \\
\text { ESS } 9 \text { versus } 4.2(p=0.028)^{b}\end{array}$ \\
\hline Morgenthaler et al. $(2014)^{15}$ & 33 & 90 days & $\begin{array}{l}\text { AHI } 4.4 / h \text { versus } 9.9 / h(p=0.0024)^{a} \\
\text { CAl } 0.7 / h \text { versus } 4.8 / h(p<0.0001)^{a} \\
\text { No significant differences in compliance, ESS or sleep apnoea QoL }\end{array}$ \\
\hline Ramar et al. $(2013)^{20}$ & 106 & Titration & $\begin{array}{l}\text { AHI } 11.0 / \mathrm{h} \text { versus } 38 / \mathrm{h} \text { at diagnosis } \\
\mathrm{AHI}<10 / / \mathrm{h} \text { in } 81 \% \text { of pts receiving ASV }\end{array}$ \\
\hline Brown et al. $(2011)^{19}$ & 25 & 1 night & $\begin{array}{l}\text { AHI 3.6/h versus } 44.4 / h r(p<0.0001)^{b} \\
\text { CAI 0.7/h versus } 34.8 / h(p<0.001)^{b}\end{array}$ \\
\hline Allam et al. $(2007)^{18}$ & 100 & 1 night & $\begin{array}{l}\text { AHI (ASV versus CPAP) } 5 / h \text { versus } 31 / h(p<0.0001)^{b} \\
\text { AHI (ASV versus bi-level) } 5 / h \text { versus } 15 / h(p<0.0001)^{b}\end{array}$ \\
\hline
\end{tabular}

${ }^{a}$ Compared with control; ${ }^{b}$ Compared with baseline. $A H I=$ apnoea-hypopnoea index; $A S V=$ adaptive servo-ventilation; $C A I=$ central apnoea index; CPAP = continuous positive airway pressure; ESS = Epworth Sleepiness Scale; $Q O L=$ quality of life; $S D B=$ sleep-disordered breathing.

cardiac death is lower. However, larger long-term studies with hard clinical outcomes (e.g. mortality) are required to definitely answer this question. Until such data are available, the decision about whether to use ASV for the treatment of CSA in patients with HFpEF needs to be made on an individual patient basis, with management by a cardiologist (see below for recommendation on monitoring ASV therapy).

\section{Adaptive Servo-Ventilation Therapy in Sleep Apnoea}

Treatment-emergent Central Sleep Apnoea

Treatment-emergent CSA, previously known as complex sleep apnoea, occurs in about 5-15\% of patients who undergo PAP titration for obstructive sleep apnoea (OSA). The definition of treatment-emergent CSA is the persistence or emergence of central apnoeas and hypopnoeas during the initiation of PAP therapy without a backup respiratory rate for OSA, despite significant resolution of obstructive respiratory events. ${ }^{11}$ For most patients, treatment-emergent CSA is a transitory phenomenon that is not stable over time.12-14 One possible explanation is that the sleep fragmentation and sleep stage shifts associated with CPAP titration cause ventilatory control instability. This suggestion is supported by the finding that treatment-emergent CSA occurs more frequently on nights where CPAP-treated patients sleep poorly. ${ }^{12}$ Other predisposing factors might be the presence of coronary artery disease, pre-existing central apnoeas, the severity of OSA and use of opioids. ${ }^{12,14}$ However, treatment is required for the subgroup of patients with treatment-emergent CSA that persists during continued use of CPAP or bilevel PAP (biPAP) without a back-up frequency. In such settings, ASV is the most appropriate therapy.

The effects of ASV on clinical and polysomnography (PSG) outcomes in patients with treatment-emergent CSA were compared with those of CPAP in a prospective, randomised clinical trial of 66 patients. ${ }^{15}$ After two nights of titration, AHI was 5.7/h in the ASV group versus 14.1/h in the CPAP group ( $p \leq 0.0003)$; corresponding values after 90 days' treatment were $4.4 / \mathrm{h}$ and $9.9 / \mathrm{h}(\mathrm{p}=0.0024)$. The CAl after titration was $1.1 / \mathrm{h}$ with ASV and $8.8 / \mathrm{h}$ with CPAP $(p \leq 0.0003)$, and after 90 days was $0.7 / \mathrm{h}$ versus $4.8 / \mathrm{h}$, respectively ( $p<0.0001$ ). After 90 days, ASV was successful (AHI reduced to $<10 / h)$ in a higher proportion of patients than CPAP $(89.7 \%$ versus $64.5 \%$; $\mathrm{P}<0.0214)$. However, there were no significant differences between the ASV and CPAP groups with respect to compliance, daytime sleepiness and quality of life, and this trial did not assess changes in blood gases or cardiac function. In another randomised crossover trial, ASV has been shown to be more effective than non-invasive positive pressure ventilation for normalising complex, central and mixed apnoea syndromes. ${ }^{16}$ The beneficial effects of ASV in a multicentre, prospective observational trial of 27 patients with CSA or treatment-emergent CSA included improvements in the $\mathrm{AHI}, \mathrm{CAl}$, obstructive apnoea index and arousal index during titration of therapy, changes that were maintained over 3 months of treatment. ${ }^{17}$ In addition, there was a significant reduction in the Epworth Sleepiness Scale (ESS) score during ASV (from 12.8 at baseline to 7.8; $p=0.001$ ); mean ASV adherence was $4.2 \mathrm{~h} / \mathrm{hight}$. These data are supported by the results of retrospective analyses showing that ASV is more effective than other PAP therapies with respect to reductions in the AHI and improvements in sleep quality in patients with treatment-emergent CSA. ${ }^{18-20} \mathrm{~A}$ summary of the results of studies investigating the use of ASV in patients with treatmentemergent CSA is presented in Table 1.

\section{Opioid-induced Cheyne-Stokes Respiration}

Central apnoeas have been detected using PSG in 17-24\% of patients receiving long-term opioid therapy for chronic pain.21,22 ASV therapy has been shown to improve SDB in opioid users in a number of clinical studies, and the result of a meta-analysis showed that treatment with ASV in patients with opioid-related CSA resulted in $58 \%$ of patients achieving a CAl of $<10 / h$, whereas CPAP was largely ineffective in this setting. ${ }^{23}$

Clinically significant reductions in the AHI, CAI and hypopnoea index were observed after just 1 night of ASV use in patients receiving long-term opioid therapy for non-malignant pain who had CSA in one prospective multicentre study; these improvements were maintained throughout 3 months of home ASV therapy. ${ }^{24}$ Both short- and long-term reductions in $\mathrm{AHI}$ and $\mathrm{CAI}$ during ASV therapy were also documented in another study of opioid-associated CSA, and long-term adherence with ASV therapy in this setting was good (mean $5.1 \mathrm{~h} /$ hight over a follow-up period of 9 months to 6 years). ${ }^{25}$ The proportion of responders also appears to be high, with $59.6 \%$ achieving an AHI of $<10 /$ h during ASV therapy for CSA associated with chronic opioid use. ${ }^{26} \mathrm{ASV}$ may also have the ability to improve obstructive apnoeas in this setting. ${ }^{27}$

Comparative data show that ASV is more effective at reducing central apnoeas in chronic opioid users than both biPAP and CPAP. In a small group of chronic opioid recipients who had no improvement in sleep apnoea during 1 night of CPAP therapy, use of ASV for 1 night completely eliminated central and obstructive apnoeas and reduced the hypopnoea index to 13/h, compared with an AHI of 70/h at baseline and 55/h during CPAP. ${ }^{28}$ In another study, AHI and CAl values were significantly 


\section{Table 2: Summary of Major Findings of Studies Assessing Adaptive Servo-Ventilation in Patients Receiving Chronic Opioid Therapy}

\begin{tabular}{|c|c|c|c|c|c|}
\hline $\begin{array}{l}\text { Author (Date) } \\
\text { Reference }\end{array}$ & $\mathrm{N}(\mathrm{ASV})$ & SDB Pattern & $\begin{array}{l}\text { Duration of } \\
\text { Opioid Therapy }\end{array}$ & $\begin{array}{l}\text { ASV } \\
\text { Duration }\end{array}$ & SDB Outcomes for ASV versus Control ${ }^{a}$ or Baseline ${ }^{b}$ \\
\hline Cao et al. (2014) ${ }^{29}$ & 18 & CSA (CAI $\geq 5 / h)$ & $\geq 6$ months & 1 night & $\begin{array}{l}\text { AHI } 2.5 / h \text { versus } 50.3 / h^{b} \\
\text { AHI } 2.5 / h \text { versus } 16.3 / h(p=0.0291)^{a} \\
\text { CAI } 0.4 / h \text { versus } 13.0 / h^{b} \\
\text { CAI } 0.4 / h \text { versus } 9.4 / h(p=0.0002)^{a} \\
\text { Al 0.4/h versus } 11.0 / h(p<0.0001) a \\
\text { Arl } 24.4 / h \text { versus } 30.7 / h(p=0.0304)^{a} \\
\text { Respiratory parameters normalised in } 83.3 \% \text { versus } 33.3 \% \text { of patients }{ }^{a} \\
\text { Patients felt more awake after ASV versus control }(p=0.0377)^{a}\end{array}$ \\
\hline Javaheri et al. $(2014)^{25}$ & 20 & CSA (CAI $\geq 5 / h)$ & 'Chronic' & 1 night & $\begin{array}{l}\text { AHI } 11 / h \text { versus } 61 / h(p=0.0001)^{b} \\
\text { CAI } 0 / h \text { versus } 32 / h(p=0.0004)^{b} \\
\text { Arl } 12 / h \text { versus } 29 / h(p=0.002)^{b} \\
\text { Minimum oxygen saturation } 90 \% \text { versus } 83 \%(p=0.0001)^{b}\end{array}$ \\
\hline Farney et al. $(2008)^{27}$ & 22 & CSA & $\geq 6$ months & NR & $\begin{array}{l}\text { AHI } 54.2 / h \text { versus } 66.6 / h^{b} \\
\text { OAI } 2.4 / h \text { versus } 25.8 / h(p<0.001)^{b} \\
\text { CAI } 15.6 / h \text { versus } 26.4 / h^{b} \\
\text { HI } 35.7 / h \text { versus } 14.5 / h(p<0.001)^{b} \\
\text { ODI } 20.8 / h \text { versus } 31.2 / h^{b}\end{array}$ \\
\hline Javaheri et al. $(2008)^{28}$ & 5 & SDB & $2-5$ years & 1 night & $\begin{array}{l}\text { AHI } 20 / h \text { versus } 70 / h(p=0.006)^{b} \\
\text { CAI } 0 / h \text { versus } 26 / h(p=0.01)^{b} \\
\text { HI } 20 / h \text { versus } 36 / h(p=0.04)^{b} \\
\text { Arl } 24 / h \text { versus } 62 / h(p=0.02)^{b} \\
\text { RDI } 16 / h \text { versus } 58 / h(p=0.01)^{b} \\
\text { ASV also significantly better versus CPAP for reductions in AHI and CAI }\end{array}$ \\
\hline
\end{tabular}

${ }^{a}$ Compared with control; ${ }^{b} \mathrm{Compared}$ with baseline. $\mathrm{Al}=$ apnoea index; $\mathrm{AHI}=$ apnoea-hypopnoea index; $\mathrm{Arl}=$ arousal index; $\mathrm{ASV}=$ adaptive servo-ventilation; $\mathrm{CAl}=\mathrm{central}$ apnoea index; CompSA = complex sleep apnoea; $C P A P=$ continuous positive airway pressure; $C S A=$ central sleep apnoea; $H I=$ hypopnoea index; $N R=$ not reported; $O A I=$ obstructive apnoea index; ODI = oxygen desaturation index; $R D I=$ respiratory disturbance index; $S D B=$ sleep-disordered breathing.

lower during short-term use of ASV compared with spontaneous-timed mode biPAP (biPAP-ST) $(2.5 / \mathrm{h}$ versus $16.3 / \mathrm{h} ; \mathrm{p}=0.0005$ and $0.4 / \mathrm{h}$ versus $9.4 / h ; p=0.0002$, respectively). ${ }^{29}$ In this prospective, crossover trial, the proportion of patients who had normalised respiratory parameters was $83.3 \%$ during ASV and $33.3 \%$ during bilevel-ST, and scores on the Morning After Patient Satisfaction Questionnaire showed that patients felt more awake after ASV versus bilevel-ST treatment $(\mathrm{p}=0.0337) .{ }^{29}$ The results of studies investigating the use of ASV in patients with sleep apnoea receiving long-term opioid therapy are summarised in Table 2.

\section{Idiopathic Cheyne-Stokes Respiration}

In some cases, despite extensive investigations, no obvious cause for CSA-CSR is found and this is referred to as idiopathic CSR, the exact prevalence of which is unknown. The feasibility of using ASV to treat idiopathic CSR was assessed in three patients who had not responded well to CPAP and oxygen therapy. ASV treatment reduced the abnormal events index from $35.2 / \mathrm{h}$ to $3.5 / \mathrm{h}$, and there was also a significant reduction in the number of arousals (18.5/h to $1.1 / \mathrm{h})$. Importantly, follow-up at 6-12 months showed a significant improvement in daytime alertness and mood in ASV recipients. ${ }^{30}$

\section{Sleep Apnoea after Ischaemic Stroke}

SDB can be documented in between $50 \%$ and $70 \%$ of patients after acute ischaemic stroke ${ }^{31,32}$ and persists beyond the acute period in a substantial proportion of patients. ${ }^{33}$ The role of ASV for the treatment of persistent CSA after acute ischaemic stroke was investigated in 15 patients, 13 of whom had previously been unsuccessfully treated with CPAP or biPAP. ${ }^{34} \mathrm{AHI}$ was $46.7 / \mathrm{h}$ at baseline, and decreased to 8.5/h ( $p=0.001)$ and $10.7 / \mathrm{h}(\mathrm{p}=0.024)$ after 3 and 6 months of ASV, respectively. ASV also improved daytime sleepiness, with a decrease in the ESS score from 8.6 at baseline to 5.6 during ASV ( $p=0.08)$. In patients who used ASV for $\geq 5 \mathrm{~h} / \mathrm{hight}$, the ESS score decreased from 9.0 at baseline to $4.2(p=0.028)$. ASV usage during the trial was good, with an average of 5 hours 20 minutes per night at 3 months and 6 hours 22 minutes per night at 6 months. ASV was also well tolerated and no severe side effects were reported.

\section{When Not to Use Adaptive Servo-Ventilation}

As has always been the case, ASV should not be used in any situation where hypoventilation is present in the basal state. Therefore, blood gases should be checked before treatment initiation, as for any other ventilation strategy. In addition, based on the results of the SERVE-HF study, ASV is now contraindicated in patients with HFrEF (left ventricular EF of $45 \%$ or less) and predominant CSA. Any current ASV recipients who meet these criteria should be advised of the SERVE-HF results and their implications and switched to an alternative mode of therapy.

\section{Monitoring Therapy}

There are currently no published guidelines on patient monitoring and follow-up during ASV therapy. Therefore, physicians need to use their clinical practice experience and common sense. Before treatment initiation, it would seem appropriate to check for HF symptoms, carefully review the patient's medical history (paying special attention to cardiac events) and, if in doubt, determine the left ventricular EF using echocardiography (especially in patients who may have cardiovascular disease). Short-term follow-up should involve 
checking for leaks, side effects and adherence to therapy. Assessment of treatment efficacy with polygraphy or PSG after 1-3 months, and a 6-month follow-up consisting of a clinical interview, machine download and full clinical assessment seems reasonable. Ongoing echocardiographic monitoring of the EF seems prudent when ASV is used in patients with cardiac disease.

\section{Perspective and Future Directions}

An important area of ongoing research is to elucidate the pathophysiological mechanisms underlying the cardiovascular safety signal identified in HFrEF patients treated with ASV in the SERVE-HF study. This will allow identification of specific subgroups of HFrEF patients in whom ASV should be avoided, and others who may benefit from ASV therapy. Data from the SERVE-HF major substudy 5 and on-treatment analysis, the ADVENT-HF trial (NCT01128816) and ongoing registries, such as the French multicentre, prospective FACE cohort study, ${ }^{35}$ will hopefully provide some insight into the use of ASV in subgroups of HFrEF patients with CSA, patients with HFrEF and OSA or OSA with coexisting CSA and those with HFpEF and both forms of SDB. The effects of ASV in patients with acute decompensated $\mathrm{HF}$ are being investigated in the
CAT-HF study (NCT01953874). Outside of HF, more data are needed on the use of ASV in patients with different CSA phenotypes, including treatment-emergent and opioid-induced central apnoeas.

\section{Conclusion}

There are a number of unanswered questions about the current and future place of ASV therapy in patients with various forms of SDB. Based on the results of the SERVE-HF study, ASV therapy should be avoided in patients with HFrEF and predominant CSA with CSR, and when ASV is used in other indications close patient monitoring is recommended, especially in subgroups at risk of developing HF. However, currently available data do suggest that ASV has beneficial effects in patients with treatment-emergent CSA, central apnoeas associated with long-term opioid therapy without alveolar hypoventilation, idiopathic CSR, after ischaemic stroke, and in those with HFpEF. Long-term data on the effects of ASV on morbidity and mortality in these patient groups are not yet available and therefore initiation of treatment is a decision that should be made individually for each patient, and therapy continued only if the patient shows subjective and objective improvements during treatment.

ADVENT-HF $=$ The Effect of Adaptive Servo-Ventilation on Survival and Hospital Admissions in Heart Failure

CAT-HF = Cardiovascular Improvements with MV ASV Therapy in Heart Failure

FACE $=$ French Cohort Study of Chronic Heart Failure Patients with Central Sleep Apnoea Eligible for Adaptive Servo-Ventilation

SERVE-HF = Treatment of Sleep-Disordered Breathing with Predominant Central Sleep Apnea by Adaptive Servo-Ventilation in Patients with Heart Failure

1. Teschler $H$, Dohring J, Wang YM, Berthon-Jones $M$, Adaptive pressure support servo-ventilation: a novel treatment for Cheyne-Stokes respiration in heart failure, Am J Respir Crit Care Med, 2001;164:614-9.

2. Javaheri S, Brown LK, Randerath WJ, Clinical applications of adaptive servoventilation devices: part 2, Chest, $2014 ; 146: 858-68$

3. Javaheri S, Brown LK, Randerath WJ, Positive airway pressure therapy with adaptive servoventilation: part 1: operational algorithms, Chest, 2014;146:514-23.

4. Cowie MR, Woehrle H, Wegscheider K, et al., Adaptive servoventilation for central sleep apnea in systolic heart failure, N Engl J Med, 2015;373:1095-105.

5. Cowie MR, Woehrle $\mathrm{H}$, Wegscheider $\mathrm{K}$, et al., Rationale and design of the SERVE-HF study: treatment of sleep-disordered breathing with predominant central sleep apnoea with adaptive servo-ventilation in patients with chronic heart failure, Eur J Heart Fail, 2013;15:937-43.

6. Bhatia RS, Tu JV, Lee DS, et al., Outcome of heart failure with preserved ejection fraction in a population-based study, N Eng/ J Med, 2006;355:260-9.

7. Borlaug BA, Redfield MM, Diastolic and systolic heart failure are distinct phenotypes within the heart failure spectrum, Circulation, 2011;123:2006-13; discussion 2014

8. MCMurray JJ, Adamopoulos S, Anker SD, et al.; Guidelines ESCCfP. ESC guidelines for the diagnosis and treatment of acute and chronic heart failure 2012: The Task Force for the Diagnosis and Treatment of Acute and Chronic Heart Failure Diagnosis and Treatment of Acute and Chronic Heart Failure 2012 of the European Society of Cardiology. Developed in collaboration with the Heart Failure

Bitter T, Westerheide N, Faber L, et al., Adaptive servoventilation in diastolic heart failure and Cheyne-Stokes respiration, Eur Respir J, 2010;36:385-92.

10. Yoshihisa A, Suzuki S, Yamaki T, et al., Impact of adaptive servo-ventilation on cardiovascular function and prognosis in heart failure patients with preserved left ventricular ejection fraction and sleep-disordered breathing, Eur J Heart Fail, 2013;15:543-50

11. International Classification of Sleep Disorders, 3rd ed. American Academy of Sleep Medicine, Darien, IL, USA. 2014

12. Cassel W, Canisius $\mathrm{S}$, Becker $\mathrm{HF}$, et al, A prospective polysomnographic study on the evolution of complex sleep apnoea, Eur Respir J, 2011;38:329-37.

13. Dernaika T, Tawk M, Nazir S, et al., The significance and outcome of continuous positive airway pressure-related central sleep apnea during split-night sleep studies, Chest 2007:132:81-7.

14. Javaheri S, Smith J, Chung E, The prevalence and natural history of complex sleep apnea, I Clin Sleep Med 2009;5:205-11

15. Morgenthaler TI, Kuzniar TJ, Wolfe LF, et al., The complex sleep apnea resolution study: a prospective randomized controlled trial of continuous positive airway pressure versus adaptive servoventilation therapy, Sleep, 2014:37:927-34.

16. Morgenthaler TI, Gay PC, Gordon N, Brown LK, Adaptive Morgenthaler TI, Gay PC, Gordon N, Brown LK, Adaptive ventilation for central, mixed, and complex sleep apnea ventilation for central, mixed, and comp
syndromes, Sleep, 2007:30:468-75.

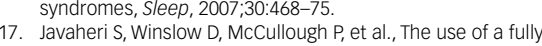
automated automatic adaptive servo ventilation algorithm in the acute and chronic treatment of central sleep apnea Chest, 2015;148:1454-61.

18. Allam JS, Olson EJ, Gay PC, Morgenthaler TI, Efficacy of adaptive servoventilation in treatment of complex and central sleep apnea syndromes, Chest, 2007;132:1839-46.

19. Brown SE, Mosko SS, Davis JA, et al., A retrospective case series of adaptive servoventilation for complex sleep apnea, J Clin Sleep Med, 2011;7:187-95.

20. Ramar K, Desrues B, Ramar P, Morgenthaler TI, Analysis of cardiopulmonary coupling to assess adaptive servoventilation success in complex sleep apnea management, Sleep Breath, 2013;17:861-6.

21. Rose AR, Catcheside PG, McEvoy RD, et al., Sleep disordered breathing and chronic respiratory failure in patients with chronic pain on long term opioid therapy, I Clin Sleep Med, 2014;10:847-52.

22. Webster LR, Choi Y, Desai H, et al., Sleep-disordered breathing and chronic opioid therapy, Pain Med, 2008;9:425-32.

23. Reddy R, Adamo D, Kufel T, et al., Treatment of opioidrelated central sleep apnea with positive airway pressure: a systematic review, J Opioid Manag, 2014;10:57-62.

24. Shapiro CM, Chung SA, Wylie PE, et al., Home-use servoventilation therapy in chronic pain patients with central sleep apnea: initial and 3-month follow-up, Sleep Breath ، 2015;19:1285-92.

25. Javaheri S, Harris N, Howard J, Chung E, Adaptive servoventilation for treatment of opioid-associated central sleep apnea, I Clin Sleep Med, 2014;10:637-43.

26. Ramar K, Ramar P, Morgenthaler TI, Adaptive servoventilation in patients with central or complex sleep apnea related to chronic opioid use and congestive heart failure, I Clin Sleep Med, 2012;8:569-76.

27. Farney RJ, Walker JM, Boyle KM, et al., Adaptive servoventilation (ASV) in patients with sleep disordered breathing associated with chronic opioid medications for non-malignant pain, J Clin Sleep Med, 2008;4:311-9.

28. Javaheri S, Malik A, Smith I, Chung E, Adaptive pressure support servoventilation: a novel treatment for sleep apnea associated with use of opioids, J Clin Sleep Med, apnea associated

29. Cao M, Cardell $C Y$, Willes $L$, et al., A novel adaptive servoventilation (ASVAuto) for the treatment of central sleep apnea associated with chronic use of opioids, I Clin Sleep Med, 2014;10:855-61.

30. Banno K, Okamura K, Kryger MH, Adaptive servo-ventilation in patients with idiopathic Cheyne-Stokes breathing, I Clin Sleep Med, 2006;2:181-6.

31. Bassetti CL, Milanova M, Gugger M, Sleep-disordered breathing and acute ischemic stroke: diagnosis, risk factors, treatment, evolution, and long-term clinical outcome, Stroke, 2006;37:967-72

32. Parra O, Arboix A, Bechich S, et al., Time course of sleeprelated breathing disorders in first-ever stroke or transient ischemic attack, Am J Respir Crit Care Med, 2000:161(2 Pt 1):375-80

33. Harbison J, Ford GA, James OF, Gibson GJ, Sleep-disordered breathing following acute stroke, QJM, 2002;95:741-7.

34. Brill AK, Rosti R, Hefti JP, et al., Adaptive servo-ventilation as treatment of persistent central sleep apnea in post-acute ischemic stroke patients, Sleep Med, 2014;15:1309-13.

35. Tamisier R, Damy T, Davy J-M, et al., Adaptive servoventilation (ASV) decreases unplanned hospitalisations in chronic hear failure (CHF) patients with central sleep apnoea (CSA): the French multicentre, prospective FACE cohort study, European Respiratory Society Congress 2015 [abstract]. 